\title{
The importance of the behaviour of young larvae in sorghum resistance to Chilo partellus
}

\author{
S. Woodhead \& S. L. Taneja \\ Tropical Development and Research Institute, College House, Wrights Lane, London W8 5SJ, U.K. and \\ International Crops Research Institute for the Semi Arid Tropics (ICRISAT), Patancheru, Andhra \\ Pradesh 502 324, India
}

Accepted: March 30, 1987

Key words: Lepidoptera, Pyralidae, Chilo partellus, spotted stem borer, resistance mechanism, larval establishment, egg infestation, larval infestation, bazooka applicator

\begin{abstract}
Management of spotted stem borer, Chilo partellus (Swinhoc) by the use of resistant cultivars is being developed at ICRISAT. Different cultivars show resistance based on several mechanisms, one of which affects the establishment of first instar larvae in the plant whorl. However, it has been found that low establishment is a factor associated with resistance only in some cultivars and not in others. A number of physical and chemical plant factors are associated with preferential establishment of the young larvae in the leaf whorl. Among the physical characteristics, erect leaves and curled leaf bases are involved in larval establishment. Detailed chemical analysis of surface extracts showed that the concentration of one compound in the wax is related to resistance at this stage and assessment of physical and chemical plant characters has been used to predict resistance.
\end{abstract}

\section{Introduction}

The spotted stem borer Chilo partellus causes serious losses to crops in many parts of Africa and India. Foliar damage by young larvae is followed by later instar stem boring, often resulting in 'deadheart' plants. Control of this insect by the use of resistant cultivars of sorghum is being developed at ICRISAT in India.

Different cultivars show resistance at various stages of plant growth and to different developmental stages of the insect. For example, some cultivars will be heavily damaged by leaf feeding, but will suffer little subsequent stem boring and vice versa. Life table studies for the insect on sorghum have shown that highest mortality occurs in the newly hatched larvae (Roome \& Padgham, 1977). Larvae hatch, generally at dawn when weather conditions are most favourable, from eggs laid on leaves near to the base of the plant (Chapman et al., 1983; Roome \& Padgham, 1977). They then climb up the plant to the whorl where feeding can begin. The climb is hazardous and success is mediated by both weather conditions and plant characteristics (Bernays et al., 1983).

Varietal differences in successful establishment in the plant have been observed in a detailed study of two cultivars, IS 1151 and IS 2205 (Bernays et al., 1983; Chapman et al., 1983). A number of physical and chemical plant factors were implicated in resistance mechanisms. The present method of screening for stem borer resistance at ICRISAT involves delivering a standard number of newly hatched larvae directly into the plant whorl (Taneja \& Leusch- 
ner, 1985). Thus any resistance of the plant due to factors that affect the initial climb to the whorl will be excluded.

In the present paper we have extended this work to assess the importance of the initial phase of larval life on damage to sorghum, and whether it should be included in resistance screening methods.

\section{Materials and methods}

The field trials were done at ICRISAT in both the rainy (Kharif) and post-rainy (Rabi) seasons of 1982 - 1984. All insects used were from the Sorghum Entomology mass rearing facility (Taneja \& Leuschner, 1985) and were obtained for these experiments at the 'blackhead' stage of egg development i.e. fully developed eggs due to hatch at dawn on the following day. All agronomic practises such as land preparation, fertilisation, irrigation etc. were by standard methods practised at ICRISAT. Seeds of all cultivars used were obtained from the Sorghum Entomology Programme, ICRISAT.

Establishment experiments. In the 1983 post-rainy season, six replicates of each of three cultivars, CSH1, IS 1151 and IS 2205 were planted in a randomised block design of $20 \times 9 \mathrm{~m}$ rows at $75 \mathrm{~cm}$ row spacing. Twenty plants were selected in each block and infested 26 days after emergence (at the 5-7 leaf stage) with blackhead egg masses. Plants infested were at least one metre apart, with two rows separating infested rows. The eggs were counted and pinned to the adaxial surface of one of the lower leaves. The number of eggs per mass was between 20 and 40. Eggs were put out in the late afternoon of the day prior to hatching. In the 1984 post-rainy season, twenty cultivars were planted in plots of $8 \times$ $9 \mathrm{~m}$ at $75 \mathrm{~cm}$ row spacing, with a replicate planting 30 days later. Infestations were done 15 days after emergence on 24 plants of each cultivar. Day of infestation was selected on the basis of plant growth: plants at the 5-7 leaf stage being selected for infestation. Growth rate differed from season to season.

Unhatched eggs were recounted and plants were destructively sampled $24 \mathrm{~h}$ after hatching. The num- bers of larvae in the whorl, behind sheaths or elsewhere on the plant were recorded for the infested plant and for five plants on either side, and for the same number of plants in the first row downwind.

Assessment of physical resistance characteristics. In previous work a number of physical characteristics of the plant have been observed to affect larval success in reaching the whorl (Bernays et al., 1983; Bernays et al., 1985). Plants were visually inspected for the following characteristics in 1984: (i) orientation of leaf to stem, (ii) elongation of internodes, (iii) curled leaf bases, (iv) leaf sheaths detached from the culm. Varieties were simply scored with a zero or a score of one if they exhibited a particular characteristic. Thus a cultivar with plants showing all four positively would be scored four, and a cultivar showing none would be scored overall zero.

(i) Orientation of leaf to stem: a small angle between leaf and stem (i.e. upright leaves) affects the insect's ability to reach the whorl. Plants were scored zero if the angle formed by the leaf and the stem was greater than approximately $45^{\circ}$, and scored one if less.

(ii) Internode length between leaves three and four was considered elongated if greater than $10 \mathrm{~cm}$, and scored one.

(iii) Cultivars were scored one if the leaf bases were sufficiently curled to accommodate a first instar larva. No attempt was made to measure this feature.

(iv) Detachment of the leaf sheath from the culm was scored one.

The total score for physical resistance factors gives equal weight to each. No attempt has been made in these experiments to weight them.

Extraction and analysis of surface chemicals. Plants with no obvious feeding damage were uprooted and any moist ure removed with cotton wool. Aerial parts were then dipped into AnalaR chloroform or $\mathrm{n}$ hexane for $30 \mathrm{~s}$. Extracts were made in the field between $08.00 \mathrm{~h}$ and $10.00 \mathrm{~h}$ and filtered through glass wool to remove any particles of soil or other contaminants. The extracts were then allowed to concentrate to small volume, and the concentrated extracts transferred to small thick walled glass phials and dried under a stream of nitrogen. 
Samples were analysed by gas chromatography (gc) without further purification. A column of $3 \%$ OV17 on Chromosorb WHP, mesh 80-100, was used in a Packard model 439 gc equipped with a flame ionisation detector at $270^{\circ}$ and temperature programme of $200^{\circ}$ to $300^{\circ}$ at $8 \% \mathrm{~min}$. Standards of 16 to 34 carbon $n$-alkanes were used for chain length comparison. Chemical resistance was assessed by measurement of a 32 carbon compound (see Woodhead, 1987, in press). The concentration of this compound was estimated as a percentage of the total compounds of chain length 16 to 34 carbon atoms.

The concentration of the $32 \mathrm{C}$ marker in extracts of CSHI ranged from $7.5-11 \%$ of the total, in IS $1151,6.5-10.5 \%$ and in IS $2205,3-5 \%$. In any series of extracts made from samples collected on the same day, the ratio of the $32 \mathrm{C}$ marker in the three varieties was constant, approximately 1:2 for IS 2205:CSHI or IS 1151. Thus cultivars with a concentration of 32 C compound higher or similar to that of IS 1151 or CSH1 were scored one, since a low score indicates a low chemical resistance, despite the higher concentration, because it is apparently the absence or low concentration of this chemical that disorients climbing larvae (Woodhead, 1987, in press). Cultivars with a ratio of $1: 1.5$ scored two, and with $1: 2$ scored three (e.g. IS 2205). This scoring system took account of variations in the concentration of the wax chemicals on different sampling days. A series of samples on any one day always included CSH1 and IS 2205 for comparison.

Infestation by 'bazooka' method and assessment of damage. The twenty selected cultivars were planted in two sets each with three replications, in a randomised block design. One set was infested in the whorl with first instar larvae by use of the 'bazooka' applicator, as described by Taneja \& Leuschner (1985). The second set was infested by pinning 'Blackhead' eggs onto the lower leaves of every alternate plant in a row. Infestations for both sets were done 15, 25 and 35 days after crop emergence. Leaf feeding damage was recorded for all plants in both sets. Total numbers of plants and numbers of plants forming deadhearts were counted 3 weeks after infestation. Deadheart formation was used as the damage criterion since although in absolutely as- sessing the importance of the climb it may have been better to record numbers of pupae, the overriding objective of the work was to assess the importance of the climb in terms of actual resistance i.e. plant loss.

Cultivars were also screened for resistance to stem borer using ICRISAT standard procedures at Patancheru (central south India) and at Hisar in northern India (Taneja \& Leuschner, 1985). Natural populations of Chilo partellus at Hisar are sufficiently high for screening to take place under natural infestation. At Patancheru, plants were infested using laboratory reared first instar larvae of Chilo partellus by 'bazooka' application. Infestation was done at 20 days after crop emergence and stem borer damage was assessed as a percentage of deadhearts formed (Taneja \& Leuschner, 1985).

\section{Results}

In the 1983 post-rainy season the results for estab-

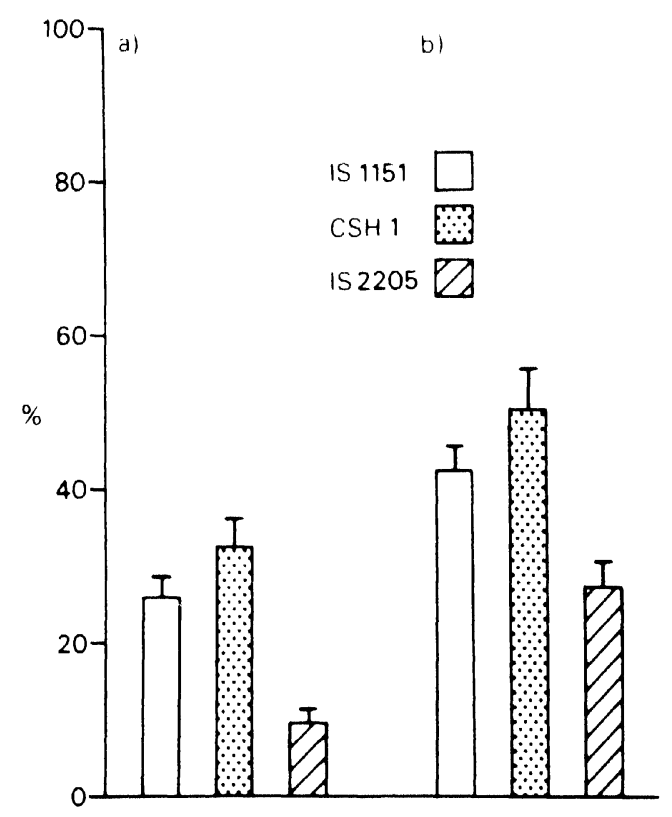

Fig. I. Recovery of larvae from infested plants and from surrounding plants at $24 \mathrm{~h}$ after infestation in 1983 post-rainy season. No. larvae recovered expressed as $\%$ of total hatch, showing mean \pm s.e.; $n=30$. a) Infested plants only; b) Total recoverd from infested plant and plants $50 \mathrm{~cm}$ to either side. 
lishment on different cultivars were similar to those of the rainy season. The highest percentages of larvae were recovered from CSH1, with slighty lower numbers from IS 1151. IS 2205 was the most resistant to establishment, with significantly fewer insects ( $t$ test, $p<0.05$ ) recovered from infested plants (Fig. la). A slightly higher number of insects were recovered from surrounding plants of $\mathrm{CSH}$ than from IS 1151 and numbers from both these cultivars were significantly higher than from IS 2205 (Fig. Ib).

The physical plant resistance characters (i-iv) correlated well with observed establishment. The leaves of IS 2205 were erect, whereas those of IS 1151 and CSH1 were set at a wider angle to the culm. On IS 2205 the leaf bases were curled, and the internodal distance was greater than on the other two varieties. For plants of this age, however, there was no indication on any cultivar of leaf sheath detachment from the culm which may have contributed to resistance.

Analysis of surface extracts of the three cultivars

Table 1. Relationship between observed resistance to larval establishment and predicted resislance.

\begin{tabular}{|c|c|c|c|c|}
\hline \multirow[t]{2}{*}{ Cultivar } & \multirow[t]{2}{*}{ Obs. resist. } & \multicolumn{3}{|c|}{ Resistance scores } \\
\hline & & Physical & Chemical & Combined \\
\hline IS 2205 & $22.0 \pm 2.0$ & 3 & 3 & 6 \\
\hline IS 12308 & $24.2 \pm 2.0$ & 3 & 3 & 6 \\
\hline IS 13100 & $26.5 \pm 3.2$ & 3 & 3 & 6 \\
\hline ICSVI & $28.6 \pm 2.8$ & 1 & 3 & 4 \\
\hline ICSV2 & $30.6 \pm 3.5$ & 1 & 3 & 4 \\
\hline IS 2195 & $32.9+3.1$ & 2 & 2 & 4 \\
\hline IS 4756 & $31.9 \pm 3.4$ & 2 & 2 & 4 \\
\hline IS 5470 & $33.9 \pm 3.1$ & 1 & 2 & 3 \\
\hline IS 5480 & $34.7 \pm 3.5$ & 1 & 2 & 3 \\
\hline IS 2123 & $33.5 \pm 4.2$ & 2 & 2 & 4 \\
\hline IS 5469 & $35.9 \pm 3.8$ & 1 & 1 & 2 \\
\hline IS 18579 & $33.1 \pm 4.2$ & 1 & 1 & 2 \\
\hline IS 18333 & $36.1 \pm 2.8$ & 3 & 1 & 4 \\
\hline IS 2309 & $36.4 \pm 3.3$ & 1 & 2 & 3 \\
\hline IS 1044 & $37.4 \pm 4.8$ & 1 & 3 & 4 \\
\hline IS 18551 & $36.1 \pm 3.3$ & 1 & 3 & 4 \\
\hline IS 18585 & $38.7 \pm 3.6$ & 1 & 1 & 2 \\
\hline IS 4476 & $40.9 \pm 3.9$ & 1 & 3 & 4 \\
\hline IS 1151 & $45.2 \pm 4.1$ & 0 & 2 & 2 \\
\hline
\end{tabular}

1 Obs. resist. mean no. larvae establishing on inoculated plant $24 \mathrm{~h}$ after hatching expressed as a percentage of no. larvae hatching on that plant, \pm s.e. by gc showed that the $32 \mathrm{C}$ 'marker' chemical was present in IS 2205 at less than half the concentration present in the other two cultivars (see Methods).

The above data indicate that, at least at the stage of growth considered here, IS 2205 should be resistant to establishment of larvae of Chilo partellus when compared to cultivars IS 1151 and CSH1.

In experiments at Patancheru in 1984, some significant differences were found in the numbers of larvae successfully establishing on the twenty cultivars selected from previous screening (see Discussion) (Table 1). Visual estimations were made of the physical resistance characters and the concentration of the 'marker' chemical in crude surface extracts was measured by gc. Resistance was predicted from a combined score based on both physical and chemical resistance characters and the highest scoring cultivars (IS 12308, IS 13100 and IS 2205) were those that were most resistant to initial establishment (Table 1).

There was good agreement also with the most susceptible cultivars. Although no experiments were done to weight the various traits, the relative importance of the chemical and physical factors is implied from results obtained for some cultivars. For example, IS 18333 had a high physical score, but a low chemical score, and its observed resistance to establishment was low (Table 1). Cultivars ICSVI and ICSV2 were among the cultivars on which the least numbers of larvae reached the whorl, as predicted from their chemical score, despite lack of physical resistance factors. However, these two cultivars were the most susceptible to stem borer in terms of deadhearts in infestations with both eggs and bazooka (Table 2).

By infesting a series of plants with eggs and another series with larvae in the whorl, it is possible to estimate how important the initial climb is in terms of deadhearts and ultimate yield loss. Fewer deadhearts from egg infestations should indicate resistance to initial establishment. The infestations were done 15 , 25 and 35 days after emergence. Egg mass size was restricted to 20-30 eggs per mass and bazooka infestations were repeated two or three times to give totals of 18-24 larvae per whorl (Taneja \& Leuschner, 1985). This gave approximately similar numbers of larvae initially on each plant. The incidence in terms 
of deadhearts was greatest from the 15 day infestation, decreasing as infestation was delayed for all cultivars including susceptibles. Since most damage was caused by infestation at 15 days, and also because previous work had demonstrated that resistance to establishment can change with increasing plant age (Bernays et al., 1983), it was decided to concentrate on data from these infestations.

Eight cultivars showed significantly fewer deadhearts from egg infestation than larval infestation at 15 days (Table 2). Two of these, IS 12308 and IS 13100 , were predicted from both chemical and physical properties to be resistant to larval establishment through climbing and had the lowest numbers of larvae reaching the whorl (Table 1). For these cultivars the data suggest that the climb to the whorl is important in overall resistance and that this element of resistance can be predicted. IS 13100 and IS 12308 also

Table 2. Reaction to stemborer of selected cultivars infested at 15 days after emergence with first instar larvae (bazooka) and eggs (Patancheru, Rabi, 1984).

\begin{tabular}{lll} 
Cultivar & \multicolumn{2}{l}{$\begin{array}{l}\text { Stemborer incidence } \\
(\% \text { deadhearts })\end{array}$} \\
\cline { 2 - 3 } & Bazooka & Eggs \\
\hline IS 1044 & 33.2 & $20.8^{*}$ \\
IS 1151 & 46.7 & $30.9^{*}$ \\
IS 2123 & 22.3 & 38.0 \\
IS 2195 & 24.5 & 36.2 \\
IS 2205 & 22.9 & 27.3 \\
IS 2309 & 29.9 & 35.6 \\
IS 4756 & 38.4 & 40.8 \\
IS 4776 & 23.7 & 34.3 \\
IS 5469 & 39.9 & $26.0^{*}$ \\
IS 5470 & 39.2 & $18.5^{*}$ \\
IS 5480 & 29.7 & 35.2 \\
IS 12308 & 37.3 & $30.6^{*}$ \\
IS 13100 & 41.2 & $18.6^{*}$ \\
IS 18333 & 43.4 & 44.1 \\
IS 18551 & 33.9 & $26.0^{*}$ \\
IS 18579 & 37.0 & 44.9 \\
IS 18585 & 21.3 & $15.5^{*}$ \\
ICSV1 & 71.5 & 76.4 \\
ICSV2 & 89.1 & 84.3 \\
CSH1 & 35.4 & 43.7 \\
\hline
\end{tabular}

* egg infestation significantly lower in deadhearts than larval infestation (ANOVA, p < 0.05).
Table 3. Reaction of selected sorghum lines to stem borer under natural (Hisar) and artificial (Patancheru) infestation, rainy scason 1983.

\begin{tabular}{|c|c|c|}
\hline \multirow[t]{2}{*}{ Cultivar } & \multicolumn{2}{|c|}{$\begin{array}{l}\text { Stemborer incidence } \\
\text { ( } \% \text { deadhearts) }\end{array}$} \\
\hline & Hisar & Patancheru \\
\hline IS 1044 & 16.7 & 20.8 \\
\hline IS 1151 & -1 & -1 \\
\hline IS 2123 & 16.5 & 19.5 \\
\hline IS 2195 & 43.3 & 23.6 \\
\hline IS $2205^{*}$ & 22.2 & 41.5 \\
\hline IS $23(09$ & 41.0 & 15.4 \\
\hline IS 4756 & 55.4 & 21.5 \\
\hline IS 4776 & 32.7 & 42.7 \\
\hline IS 5469 & 9.5 & 11.0 \\
\hline IS 5470 & 46.0 & 19.3 \\
\hline IS 5480 & 27.0 & 46.1 \\
\hline IS 12308 & 15.2 & 22.4 \\
\hline IS $13100^{2}$ & 4.7 & 34.1 \\
\hline IS $18333^{2}$ & 15.8 & 62.8 \\
\hline IS $18551^{2}$ & 17.9 & 42.5 \\
\hline IS 18579 & 22.2 & 34.3 \\
\hline IS 18585 & 29.7 & 46.7 \\
\hline ICSVI & 88.8 & 71.6 \\
\hline ICSV2 & -1 & -2 \\
\hline $\mathrm{CSHI}$ & 62.5 & 52.4 \\
\hline
\end{tabular}

1 data not available; ${ }^{2}$ cultivars with significantly higher deadhearts under artificial infestation as compared to natural infestation (ANOVA, $p<0.05$ ).

suffered fewer deadhearts in field trials under natural infestation at Hisar (Table 3), suggesting that, for this cultivar, low initial establishment through the climb to the whorl is an effective resistance mechanism. IS 2205 performed similarly (Tables 2 and 3), but there was no significant difference between deadhearts formed as a result of egg and bazooka infestations (Table 2). Cultivars ICSV 1 and ICSV 2 (see above), although showing resistance to initial establishment, were the most susceptible cultivars tested and there was no difference in percentage of deadhearts between the methods of infestation (Tables 1 and 2). This suggests that, in contrast to IS 12308 and IS 13100, low initial establishment of larvae in these cultivars is not important in overall susceptibility. IS 1151 was predicted to give good larval establishment and this was borne out by 1984 rainy season 
establishment experiments. However, although IS 1151 was the most susceptible after ICSV 1 and ICSV 2 in the larval infestation, fewer deadhearts were recorded from comparable egg infestations (Table 2).

In varieties IS 18585 and IS 5469, deadhearts were significantly lower in egg than larval infestations. This was not expected from the low resistance scores and relatively high numbers of insects reaching the whorl. Damage in these two cultivars was also low, suggesting the involvement of other mechanisms.

\section{Discussion}

Detailed studies in the 1980 and 1981 rainy seasons at ICRISAT with cultivars IS 1151 and IS 2205 showed that initial establishment of newly hatched larvac of Chilo partellus was significantly higher on IS 1151 than on IS 2205 for young plants up to about the 5-7 leaf stage. Although more insects dispersed from the plant on which they hatched for IS 2205 , fewer were able to establish on adjacent plants, presumably because they encountered the same difficulties experienced on the original plant on which they hatched. Results obtained for these cultivars in the 1983 and 1984 post-rainy seasons were similar to those in the rainy season, implying that factors affecting the initial establishment of larvae in the whorl are largely independent of season.

Both physical and chemical characteristics of the plants have been shown to be involved in preferential establishment (see Methods, Bernays et al., 1983; 1985). IS 2205 has erect leaves, whereas both IS 1151 and $\mathrm{CSHI}$ have 'floppy' leaves, oriented such that the angle between the leaf and stem is much larger than on IS 2205. This characteristic has been shown to influence larvae in their climb up the culm, erect leaves causing larvae to move out onto them and thus disperse from the tips, whereas the shadow cast by floppy leaves is avoided and the larvae thus stay on the culm (Bernays et al., 1985). The bases of IS 2205 leaves are more curled than the other two cultivars and provide a refuge for climbing larvae, simulating whorl conditions. Some larvae stay here instead of progressing to the whorl and thus lose their positive phototaxis and may never reach the whorl (Bernays et al., 1985). IS 2205 is a taller cultivar than the others and therefore insects have farther to climb so will be exposed for longer periods to possible predators, the effects of dehydration and adverse environmental conditions (Chapman et al., 1983).

There is little obvious difference in the degree of detachment of the sheaths of young plants of these three cultivars but in older plants the sheaths of IS 1151 come away from the stem easily and this may account for the increased relative resistance to establishment (Bernays et al., 1983). More larvae can go behind the sheaths where they stay instead of climbing to the whorl. However, although it has been assumed that the stem tissue behind the sheath, and the sheath itself, are too tough for feeding by first instar larvae, this has not been demonstrated unequivocally.

Chemical characteristics of the plant surface have also been implicated in the resistance of young plants of IS 2205 (Bernays et al., 1985). Insects are apparently disoriented as they crawl over the surface of IS 2205, whilst on CSHI and IS 1151 the positive phototactic response is apparently reinforced by perception of surface components that indicate its host plant.

Gas chromatographic analysis of surface extracts from the three cultivars has shown that there are significant differences in concentration of a compound with a 32 carbon chain length (32 C marker) which could account for the observed differences in behaviour when stem borer larvae crawl over the surface of these plants, or over surface extracts is bioassay (Woodhead et al., 1987, in press). It is thought that the absence of a sufficiently high concentration of this chemical from the plant wax disorients the insect.

Before the resistance characteristics can be considered in terms of methods of screening in a plant breeding programme it is necessary to see how widely they are distributed and how their occurrence coincides with observed resistance to the insect. In 1984 twenty cultivars of sorghum were selected from hundreds tested in several seasons at ICRISAT Centre, Patancheru and at the ICRISAT station at Hisar.

The cultivars were selected on the basis of their resistance to stem borer under natural (Hisar) and artificial (Patancheru) infestation (Table 3). IS 1151 
was included because it had been used in earlier experiments for comparison with the resistant IS 2205 (Bernays et al., 1983; Woodhead et al., 1983). In addition, three susceptible cultivars, ICSV 1, ICSV 2 and $\mathrm{CSH} 1$ were included. Deadhearts due to natural attack by stem borer were recorded in field trials at $\mathrm{Hi}$ sar, and these were compared to numbers of deadhearts recorded on the same cultivars artificially infested with stem borer larvae using the 'bazooka' applicator. Overall IS 2205, IS 18333, IS 18551 and IS 13100 showed a higher resistance to deadheart formation under natural conditions (Table 3). Since artificial infestation places live larvae directly at their feeding site, these differences may be due either to oviposition non preference, or to differences in initial larval establishment, only the latter being under consideration in this paper.

In attempting to predict resistance from scores relating to physical and chemical characters that affect initial establishment, the most resistant and most susceptible could be predicted, but the majority of cultivars did not show significant differences in larval establishment. In general, they were rated medium to high for chemical components and low for physical (Table 1), and most had comparable numbers of deadhearts from egg and larval infestations (Table 2). Most had only one physical resistance character, that of erect, narrow leaves. These characters have also been associated with resistance to shootfly (Blum, 1971). The trait is only expressed obviously in young plants up to about 15-20 days after emergence. A high chemical score is apparently more important for resistance to establishment of larvae, but only in some cases is this reflected in reduced deadheart formation. In the experiments that compare deadhearts resulting from egg infestation (which include the climbing phase) and from larval infestation (which do not), resistance can in some, but not in all cases, be predicted from factors known to affect the initial climb and establishment in the whorl.

These experiments, therefore, show that there are resistance mechanisms to stem borer other than that which affects the establishment of young larvae in the whorl. However, this mechanism has been shown to be important in about $50 \%$ of the selected varieties. Plant characteristics that determine levels of re-
Sistance iv estavis.m............

and chemically, and the score will predict the importance of this phase in subsequent damage and loss of yield. Thus inclusion of this phase of larval life in routine screening procedures (i.e. by egg infestation as opposed to bazooka) may indicate some sources of resistance that otherwise would not show up. However, it is clear that low establishment is an effective resistance mechanism only in some cultivars, where it may be reinforced by other mechanisms operating in the later stages of larval life, or in some cases at oviposition. In other cultivars, resistance at the initial stage reduces the numbers of larvae becoming established but does not affect later susceptibility, suggesting a particularly favourable plant for larval development, or a lack of tolerance. Infestation with eggs is time consuming and labour

Infestation with eggs is time consuming and labour intensive compared to larval release using the bazooka applicator. Rapid screening for resistance characters, visually and by estimating the content of crude chemical extracts by gc could be done in small plots using plants within 20 days of emergence, thus conserving land and both human and genotypic resources. Coupled with bazooka infestations, this may provide the best and the most economic approach to future screening.

\section{Résumé}

Importance du comportement des jeunes chenilles de Chilo partellus dans la résistance du sorgho

L'Institut International de Recherches sur les Cultures en Régions Semi-Arides (ICRISAT) étudie la protection contre $C$. partellus Swinhoe par l'utilisation de cultivars résistants. Différents cultivars présentent une résistance à différents stades de croissance de la plante, et à différents stades de l'insecte. La résistance du sorgho à $C$. partellus dépend de plusieurs mécanismes, l'un d'eux conditionnant l'installation des chenilles du premier stade dans le verticille de la plante. Cependant, la lenteur de l'installation d'est un facteur lié à la résistance que chez quelques cultivars. Plusiers facteurs physiques et chimiques sont associés à l'installation préférentielle des jeunes che- 
nilles dans le verticille foliare. Parmi les caractères physiques, le port érigé des feuilles, la présence de poches à leur base et les cires superficielles sont impliqués dans l'installation des chenilles. Une analyse chimique détaillée d'extraits des structures superficielles a montré que la concentration d'une substance, le C32 “marqueur" de la lignée résistante IS 2205 , était 2 fois plus faible que dans les lignées sensibles IS 1151 et CSH 1.

\section{Acknowledgements}

We thank Dr K. Leuschner and the members of the Sorghum Entomology Dept., ICRISAT. S. W. acknowledges the Director, ICRISAT, for permission to work at Patancheru.

\section{References}

Bernays, E. A., R. F. Chapman \& S. Woodhead, 1983. Behaviour of newly hatched larvae of Chilo partellus (Swinhoe) (Lepidoptera: Pyralidae) associated with their establishment in the host plant, sorghum. Bull. ent. Res. 73: 75-83.
Bernays, E. A., S. Woodhead \& L. Haines, 1985. An experimental analysis of whorl finding by newly hatched larvae of Chilo partellus (Swinhoe) (Lepidoptera: Pyralidae). Entomol. exp. appl. 39: $73-80$.

Blum, A., 1971. Sorghum breeding for shootfly resistance in Israel In Control of Sorghum Shootfly (eds. M. G. Jotwani and W. R. Young), Oxford \& IBH, New Delhi. pp. 180- 192.

Chapman, R. F., S. Woodhead \& E. A. Bernays, 1983. Survival and dispersal of young larvae of Chilo partellus (Swinhoe) (Lepidoptera: Pyralidae). Bull. ent. Res. 73: 65-74.

Roome, R. F. \& D. E. Padgham, 1977. Report on first field study period, July-Nov., 1976. COPR/ICRISAT Collaborative project on stem borer ecology and behaviour. COPR, U.K., 55 pp.

Taneja, S. \& K. Leuschner, 1985. Methods of rearing, infestation and evaluation for Chilo partellus resistance in sorghum. In: Proceedings of the International Sorghum Entomology Workshop, Texas, U.S.A. ICRISAT, Patancheru P.O., A.P. 502234 , India.: 175188

Woodhead, S., 1987. The influence of surface chemicals of sorghum on the behaviour of the stem borer Chilo partellus (Swinhoe). In: Proceedings of VI International Symposium on Insect-Plant Relationships, Pau, France. In press.

Woodhead, S., L. A. Bernays \& R. F. Chapman, 1983. Report on visits to ICRISAT in 1981 \& 1982. COPR/ICRISAT Collaborative Project on the Sorghum Stemborer. COPR, U.K., pp 42. 